USO DA ANÁLISE MULTIVARIADA COMO SUPORTE ESTATÍSTICO NA AVALIAÇÃO MACROSCÓPICA DOS IMPACTOS AMBIENTAIS EM NASCENTES NA LOCALIDADE DE CARNE DE VACA, PERNAMBUCO

\title{
USO DA ANÁLISE MULTIVARIADA COMO SUPORTE ESTATÍSTICO NA AVALIAÇÃO MACROSCÓPICA DOS IMPACTOS AMBIENTAIS EM NASCENTES NA LOCALIDADE DE CARNE DE VACA, PERNAMBUCO
}

\author{
Use of multivariate analysis as a statistical support in the macroscopic evaluation \\ of environmental impacts in springs in the town of Carne de Vaca location, \\ Pernambuco
}

\begin{abstract}
Recebido em 02/10/2020
Aceito em 27/11/2020
\end{abstract}

João Carlos Morais de Araújo Júnior Universidade Federal de Pernambuco - UFPE icmorais.araujo@gmail.com

\begin{abstract}
RESUMO: Normalmente a relação entre seres humanos e meio ambiente, particularmente os recursos hídricos, nem sempre é harmoniosa e consciente. Nesse contexto, o presente estudo tem como objetivo analisar os impactos ambientais macroscópicos observados em três nascentes localizadas em área urbana no povoado de Carne de Vaca, Pernambuco, assim como averiguar se existem modificações na qualidade ambiental das nascentes. Através do Índice de Impacto Ambiental em Nascentes e aplicação da análise de componentes principais foi possível a distinção da qualidade ambiental entre as nascentes, bem como os principais impactos ambientais atuantes nesse ecossistema. Dessa maneira, as nascentes apresentam indícios de degradação ambiental, principalmente pelo despejo irregular de resíduos sólidos, uso por humanos e por cemitérios construídos próximos das nascentes. Por meio da análise de componentes principais foram reconhecidos dois grupos com impactos ambientais distintos, o grupo 1 constituído pela nascente 3 apresenta menores impactos e maior conservação ambiental, contudo o grupo 2 formado pelas nascentes 2 e 3 indicam regiões impactadas pelas atividades antrópicas. Nesse contexto, sugerem-se atividades de fiscalização e educação ambiental para a devida conscientização das pessoas que usam essas nascentes, além da análise da qualidade dessa água para verificar se está devidamente enquadrada nos limites estabelecidos pela legislação brasileira.
\end{abstract}

Palavras-chave: Nascente; Qualidade Ambiental; Recurso Hídrico; ACP.

\begin{abstract}
Normally, the relationship between human beings and the environment, particularly water resources, is not always harmonious and conscious. In this context, the present study aims to analyze the macroscopic environmental impacts observed in three springs located in an urban area in the village of Carne de Vaca, Pernambuco, as well as to investigate whether there are changes in the environmental quality of the springs. Through the Environmental Impact Index on Springs and the application of the analysis of main components, it was possible to distinguish the environmental quality between the springs, as well as the main environmental impacts acting on this ecosystem. Thus, the springs show signs of environmental degradation, mainly due to irregular dumping of solid waste, use by humans and cemeteries built close to the springs. Through the analysis of main components, two groups with distinct environmental impacts were recognized, group 1 consisting of spring 3 presents lesser impacts and greater environmental conservation, however, group 2 formed by springs 2 and 3 indicate regions impacted by human activities. In this context, inspection and environmental education activities are suggested to raise the awareness of the people who use these springs, in addition to analyzing the quality of this water to verify that it is properly within the limits established by Brazilian legislation.
\end{abstract}

Keywords: Spring; Environmental Quality; Water Resources; PCA. 
USO DA ANÁLISE MULTIVARIADA COMO SUPORTE ESTATÍSTICO NA AVALIAÇÃO MACROSCÓPICA DOS IMPACTOS AMBIENTAIS EM NASCENTES NA LOCALIDADE DE CARNE DE VACA, PERNAMBUCO

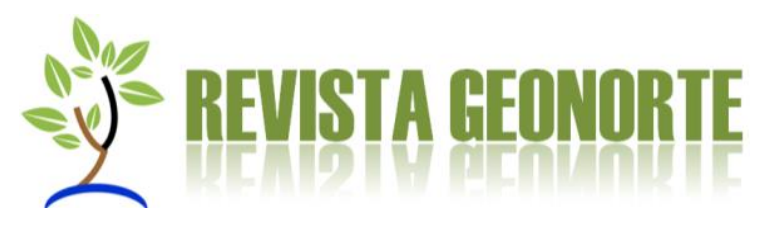

\section{INTRODUÇÃO}

A água é um recurso natural essencial para a manutenção da vida e para o desenvolvimento da sociedade, dessa maneira a qualidade da água é um dos principais fatores para o avanço socioeconômico com a devida preservação do meio ambiente (BAKER; MILLER, 2013).

As nascentes são consideradas corpos hídricos essenciais para a manutenção e formação dos rios, sendo caracterizadas como ambientes únicos e com complexibilidade ambiental pouco discutida. Normalmente as águas das nascentes são rotuladas como adequadas para o consumo humano imediato, contudo podem possuir a qualidade de suas águas inadequadas (SANTANA et al., 2016; OLIVEIRA et al., 2014).

A avaliação da qualidade da água pode ser definida através do monitoramento dos parâmetros físicos, químicos e biológicos. Tais parâmetros indicam a qualidade ambiental do corpo hídrico e ainda auxiliam os órgãos públicos para a tomada de decisões, caso o ambiente esteja degradado (CORREIO et al., 2016; MEDEIROS et al., 2016).

Estudos sobre a qualidade de nascentes são escassos, devido à grande divulgação de que são encontradas em regiões topograficamente elevadas, protegidas por matas e de difícil acesso para ocupação humana, além disso, são priorizadas pesquisas sobre rios ou bacias hidrográficas devido à sua relevância como unidade de planejamento. Contudo, o estudo sobre a qualidade das nascentes possui diversas lacunas que necessitam ser entendidas e respondidas, dado que as nascentes possuem alta relevância para o abastecimento público e a preservação de rios (SOARES e TROLEIS, 2017; SANTANA et al., 2016). Todavia, no momento presente, são debatidos sobre o nível de degradação existente nesse ecossistema e suas implicações ao meio ambiente e saúde humana.

Desta forma, a análise, o reconhecimento e classificação da conservação das nascentes são essenciais para a devida manutenção deste ecossistema e para elaboração de projetos de gestão ambiental, viabilizando informações para a tomada de decisões e a escolha de áreas prioritárias para a conservação e preservação do meio ambiente (PIERONI et al., 2019).

Nesse contexto, o presente artigo tem como objetivo avaliar e identificar os impactos ambientais macroscópicos existentes nas nascentes inseridas na localidade de Carne de Vaca (PE) e verificar se há diferenças na qualidade ambiental das nascentes.

\section{MATERIAIS E MÉTODOS}

\section{Área de estudo}

O presente estudo foi realizado na localidade de Carne de Vaca, município de Goiana, estado de Pernambuco. A região é limitada geograficamente a norte com o estado de Paraíba, a oeste por Condado, a sul com Itaquitinga, Itamaracá, Igarassu e Itapissuma, a Leste pelo Oceano Atlântico (CPRM, 2005) (Figura 1). 
USO DA ANÁLISE MULTIVARIADA COMO SUPORTE ESTATÍSTICO NA AVALIAÇÃO MACROSCÓPICA DOS IMPACTOS AMBIENTAIS EM NASCENTES NA LOCALIDADE DE CARNE DE VACA, PERNAMBUCO

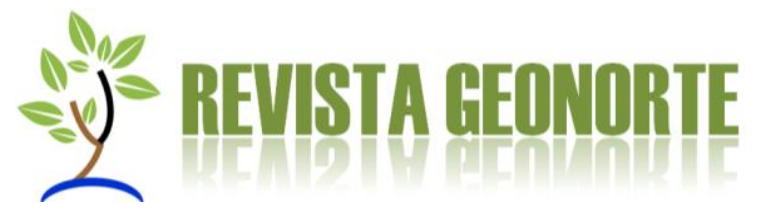

O clima da região é descrito como do tipo quente e úmido, com o período seco nos meses de setembro a fevereiro e período chuvoso nos meses de março a agosto (DANTAS et al., 2010).

Na região de estudo, as nascentes são chamadas e conhecidas pela população como "Fontes d'águas" e são utilizadas como fonte principal de captação e consumo de água por parte dos moradores.

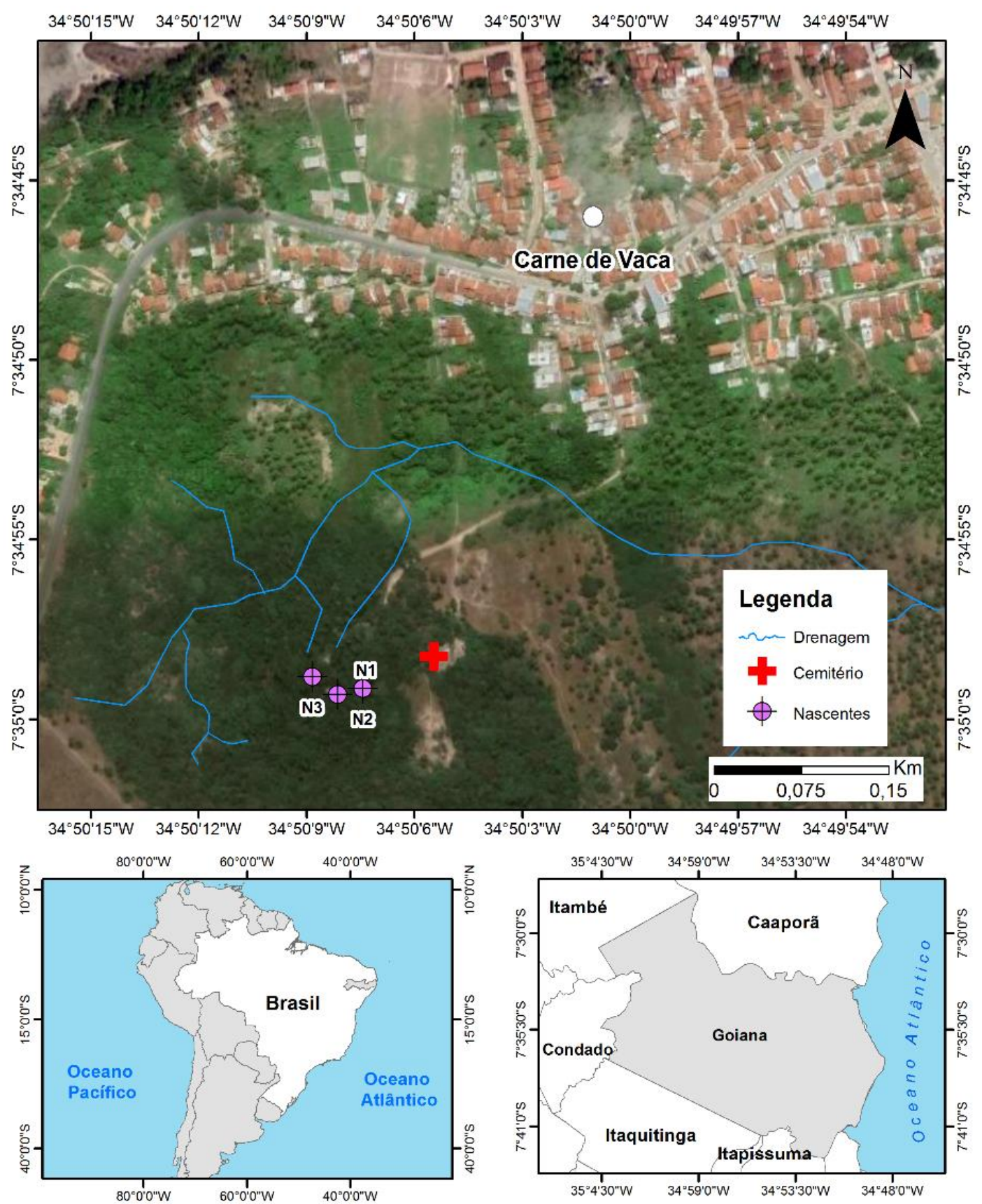

Figura 1. Localização da área de estudo e distribuição das nascentes avaliadas. Fonte: Elaborado pelo autor (2020). 
USO DA ANÁLISE MULTIVARIADA COMO SUPORTE ESTATÍSTICO NA AVALIAÇÃO MACROSCÓPICA DOS IMPACTOS AMBIENTAIS EM NASCENTES NA LOCALIDADE DE CARNE DE VACA, PERNAMBUCO

\section{Metodologia}

Os impactos ambientais foram avaliados através de observações macroscópicas das nascentes, conforme a metodologia proposta por Gomes et al. (2005).

Dessa maneira, a aplicação do Índice de Impacto Ambiental em Nascentes (IIAN) classifica o estado de conservação atual das nascentes. Foram considerados o uso de 11 parâmetros macroscópicos, sendo observados e avaliados in situ. Cada parâmetro possui três níveis de classificação e um peso específico para eles, onde: peso 1 e 2 - são atribuídos a um ambiente impactado pelas atividades antrópicas, enquanto o peso 3 é aplicado para ambientes mais conservados (PIERONI et al., 2019) (Quadro 1).

Posteriormente com as observações encontradas na área de estudo, os parâmetros macroscópicos foram quantificados e classificados de acordo com o quadro 2.

Quadro 1 - Parâmetros macroscópicos e seus respectivos pesos.

\begin{tabular}{|c|c|c|c|}
\hline Parâmetros & Peso 1 & Peso 2 & Peso 3 \\
\hline Cor da água & Escura & Clara & Transparente \\
\hline Esgoto & $\begin{array}{c}\text { Esgoto } \\
\text { doméstico }\end{array}$ & Fluxo superficial & Sem esgoto \\
\hline Espumas & Muita & Pouca & Sem espumas \\
\hline Lixo ao redor & Muito & Pouco & Sem lixo \\
\hline Odor & Cheiro forte & Cheiro fraco & Sem cheiro \\
\hline Proteção do local & Sem proteção & $\begin{array}{c}\text { Com proteção, mas } \\
\text { com acesso }\end{array}$ & $\begin{array}{c}\text { Com proteção e sem } \\
\text { acesso }\end{array}$ \\
\hline $\begin{array}{c}\text { Proximidade com residência } \\
\text { ou estabelecimento }\end{array}$ & $\begin{array}{c}\text { Menos de 50 } \\
\text { metros }\end{array}$ & $\begin{array}{c}\text { Entre 50 a 100 } \\
\text { metros }\end{array}$ & Mais de 100 metros \\
\hline Tipo de área de inserção & Ausente & Propriedade privada & Parques ou áreas \\
protegidas
\end{tabular}

Fonte: Adaptado de Gomes et al. (2005).

Quadro 2 - Classificação das nascentes em relação aos impactos macroscópicos observados.

\begin{tabular}{|c|c|c|}
\hline Classe & Nível de conservação & Pontuação final \\
\hline A & Ótimo & $31-33$ \\
\hline B & Bom & $28-30$ \\
\hline C & Razoável & $25-27$ \\
\hline D & Ruim & $22-24$ \\
\hline E & Péssimo & Menor que 21 \\
\hline
\end{tabular}

Fonte: Adaptado de Gomes et al. (2005). 
USO DA ANÁLISE MULTIVARIADA COMO SUPORTE ESTATÍSTICO NA AVALIAÇÃO MACROSCÓPICA DOS IMPACTOS AMBIENTAIS EM NASCENTES NA LOCALIDADE DE CARNE DE VACA, PERNAMBUCO

\section{Análise estatística}

A associação dos parâmetros macroscópicos que influenciam o grau de conservação das nascentes foi identificada através de análise estatística multivariada - Análise de componentes principais (ACP). A análise estatística foi realizada através do software $R$ (R CORE TEAM, 2020).

A ACP modifica o conjunto original das variáveis de dados em um novo conjunto de variáveis, designadas de componentes principais $(\mathrm{CP})$. Desta forma, este método estatístico foi utilizado para com o objetivo de reduzir o número de variáveis originando novos componentes para compreender as dependências entre as variáveis (SOUZA e SANTOS, 2018; MINGOTI, 2005).

\section{RESULTADOS E DISCUSSÕES}

A tabela 1 apresenta os resultados obtidos no levantamento de campo. A seguir será discutido cada parâmetro observado e suas implicações sobre a qualidade ambiental das nascentes.

Tabela 1 - Índice de Impacto Ambiental em Nascentes e quantificação dos parâmetros macroscópicos.

\begin{tabular}{cccc}
\hline Parâmetros & Nascente 1 & Nascente 2 & Nascente 3 \\
\hline Cor da água & 3 & 3 & 3 \\
\hline Esgoto & 3 & 3 & 3 \\
\hline Espumas & 3 & 3 & 3 \\
\hline Lixo ao redor & 1 & 2 & 2 \\
\hline Odor & 2 & 2 & 3 \\
\hline Proteção do local & 2 & 2 & 2 \\
\hline Proximidade com residência ou estabelecimento & 2 & 2 & 2 \\
\hline Tipo de área de inserção & 2 & 2 & 2 \\
\hline Uso por animais & 2 & 2 & 2 \\
\hline Uso por humanos & 1 & 1 & 1 \\
\hline Vegetação (preservação) & 2 & 2 & 2 \\
\hline Total & 23 & 24 & 25 \\
\hline
\end{tabular}

Fonte: Elaborado pelo autor (2020).

\section{Cor da água e odor}

A cor da água é ocasionada pela reflexão da luz, devido à presença de material dissolvido de origem orgânica (ácidos húmicos e fúlvicos) e pela contribuição inorgânica (óxidos de ferro e manganês), além que normalmente águas não impactadas apresentam boa transparência e são inodoras. (BRASIL, 2006). Enquanto o parâmetro odor é influenciado principalmente pelos constituintes inorgânicos em elevadas concentrações como o ferro, cloreto, sulfato, dentre outros (FERREIRA FILHO, 1996). 
USO DA ANÁLISE MULTIVARIADA COMO SUPORTE ESTATÍSTICO NA AVALIAÇÃO MACROSCÓPICA DOS IMPACTOS AMBIENTAIS EM NASCENTES NA LOCALIDADE DE CARNE DE VACA, PERNAMBUCO

A cor aparente das nascentes é classificada como incolor, contudo é observado no sistema de captação de água resíduos de coloração avermelhada. Em relação ao odor as nascentes 1 e 2 possuem cheiro fraco de material férrico. $O$ resíduo avermelhado e o odor férrico sugerem que as nascentes naturalmente possuem elevadas concentrações de óxido de ferro, contudo o carente sistema de captação de água contribui com o aumento da concentração deste material (figura 2).

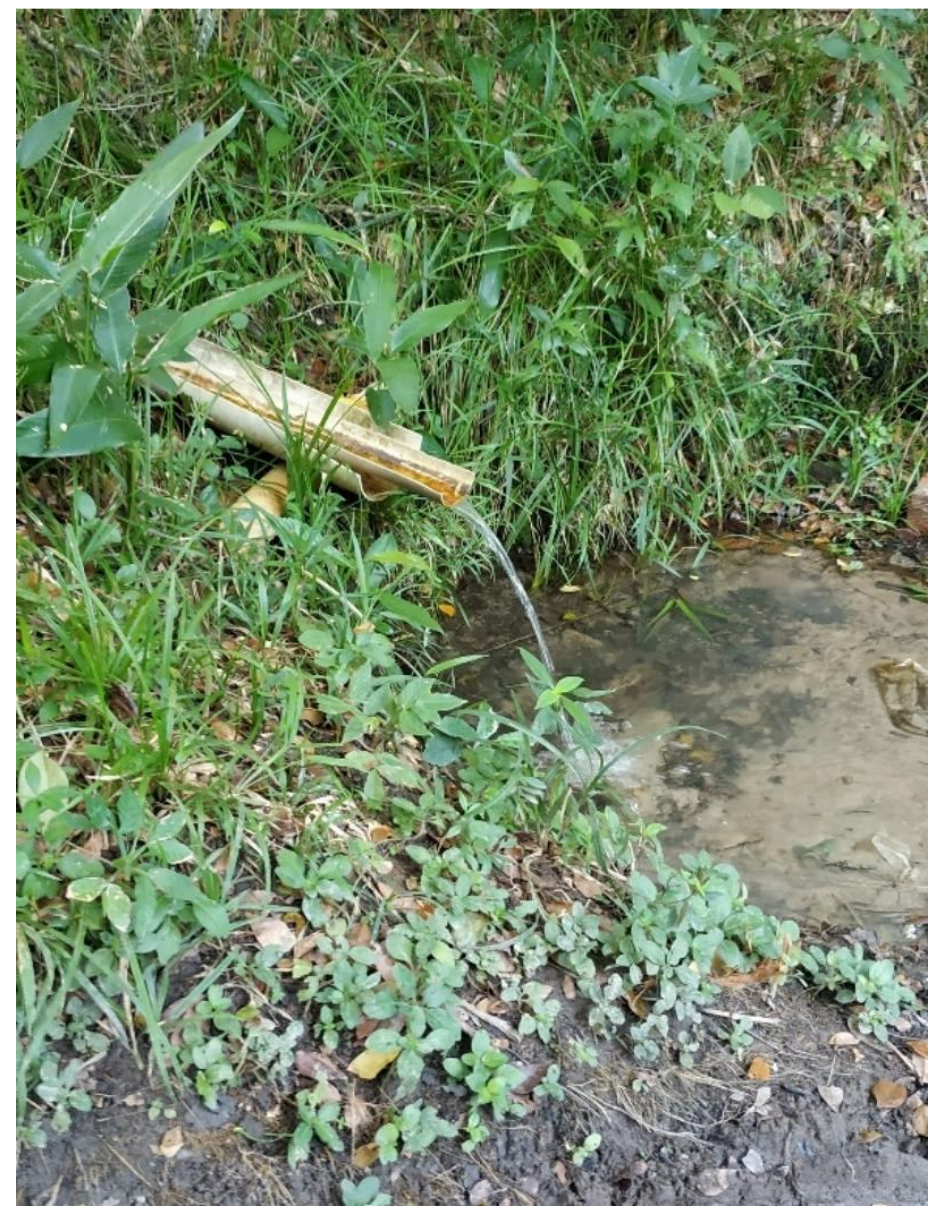

Figura 2. Sistema de captação de água com resquícios de material férrico. Fonte:

O autor.

\section{Esgoto, espumas e lixo ao redor}

As águas das nascentes não apresentam espumas e não há o lançamento de esgoto nas proximidades. Entretanto, existe o despejo irregular de resíduos sólidos ao longo das nascentes e principalmente na vegetação. Foram encontrados vários resíduos, como: papéis, latas, plástico, isopor, garrafas de vidro e plásticas, restos de alimentos, utensílios domésticos, roupas, dentre outros (Figura 3).

A presença de lixo descartado de forma irregular diretamente ao meio ambiente ocasiona a formação do chorume, líquido escuro, fétido e com alta capacidade de 
USO DA ANÁLISE MULTIVARIADA COMO SUPORTE ESTATÍSTICO NA AVALIAÇÃO MACROSCÓPICA DOS IMPACTOS AMBIENTAIS EM NASCENTES NA LOCALIDADE DE CARNE DE VACA, PERNAMBUCO

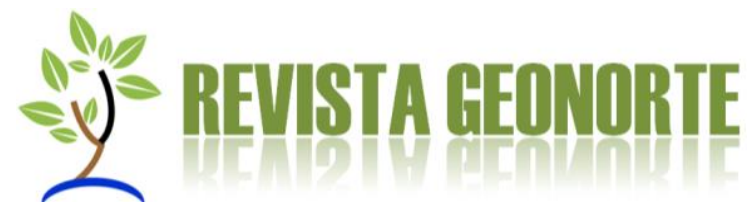

contaminação em solos e águas. Esses impactos prejudicam a saúde do meio ambiente e dos seres humanos que utilizam desta água, devido às alterações ocasionadas pelo chorume nas propriedades físicas, químicas e biológicas da água (MARTINS et al., 2017).

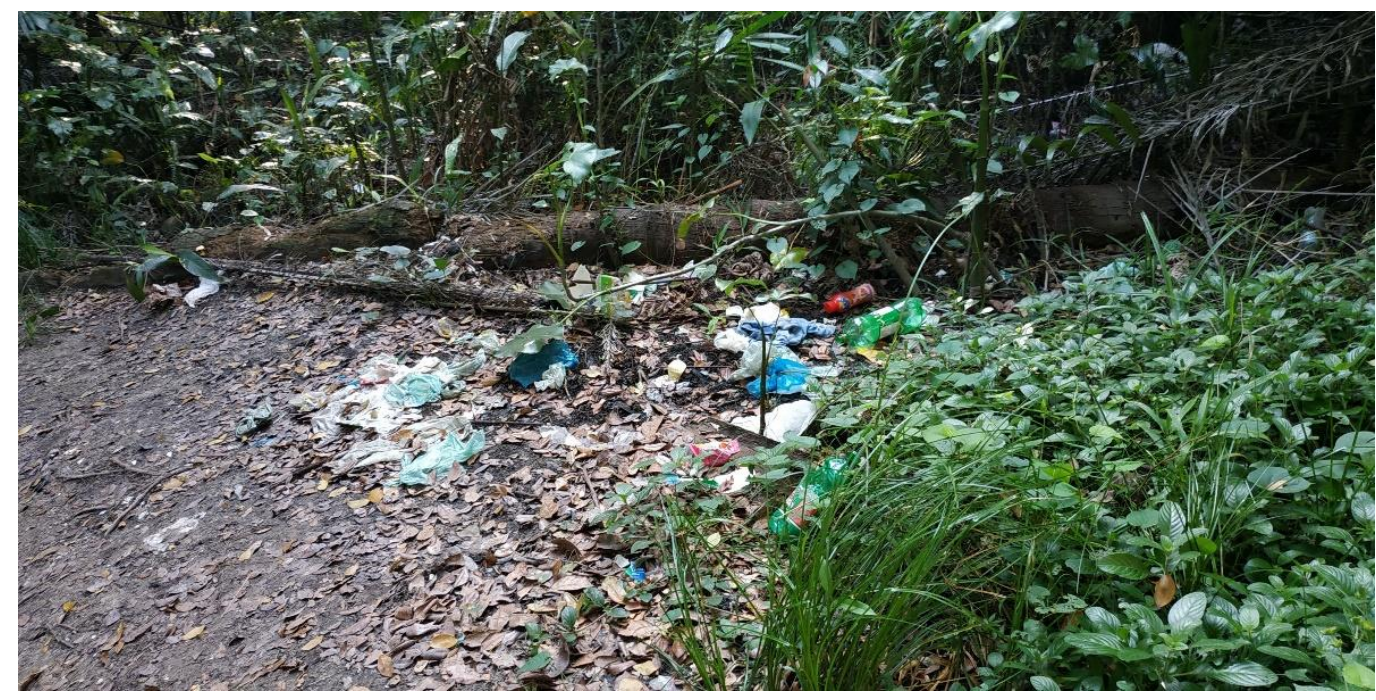

Figura 3. Presença de resíduos sólidos nas proximidades das nascentes. Fonte: O autor. Tipo de área de inserção, proteção do local e proximidade com residência ou
estabelecimento

De acordo com Gomes et al. (2005) a maior parte das nascentes são localizadas em propriedades privadas, escolas ou parques, sendo necessário realizar atividades de preservação deste corpo hídrico. Dessa forma, a proteção de nascentes frequentemente é empregada medidas para garantir a boa qualidade e quantidade da água, minimizar ou eliminar a contaminação existente (BRASIL, 2015).

A influência da presença humana é intensa em locais próximos de residências ou estabelecimentos, dessa maneira, o aumento populacional contribui ativamente com o aumento dos impactos ambientais (GOMES et al., 2005).

As nascentes estão localizadas em área particular, existe placas de aviso e cercas para limitar o acesso das pessoas, contudo há acesso facilitado para chegada nas nascentes (Figura 4). De acordo com Torres (2016) a ausência de proteção é considerada como o principal fator impactante na qualidade da água, visto que propicia na intensificação do uso antrópico. Dessa maneira, para a devida proteção e conservação das nascentes é necessário realizar três procedimentos: (i) proteger a superfície do solo para diminuir o processo de erosão; (ii) propiciar condições adequadas para a infiltração superficial da água para melhorar o abastecimento da água subterrânea; (iii) diminuição dos níveis de evapotranspiração para que a água

REVISTA GEONORTE, V.11, N.38, p.110-124, 2020.

DOI: 10.21170/geonorte.2020.V.11.N.38.110.124

(ISSN 2237 - 1419) 
USO DA ANÁLISE MULTIVARIADA COMO SUPORTE ESTATÍSTICO NA AVALIAÇÃO MACROSCÓPICA DOS IMPACTOS AMBIENTAIS EM NASCENTES NA LOCALIDADE DE CARNE DE VACA, PERNAMBUCO

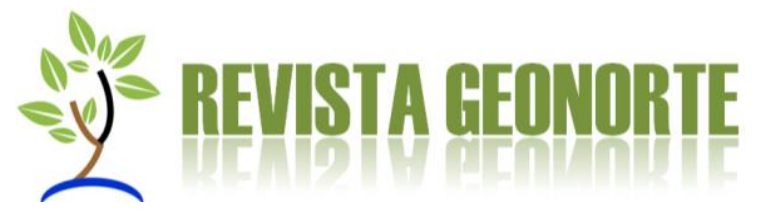

acumulada nos reservatórios subterrâneos possua a vazão adequada (CASTRO; LIMA e LOPES, 2007).

Outro fator extremamente preocupante é a presença de cemitérios nas proximidades das nascentes. Frequentemente são encontrados diversos impactos ambientais referentes às águas superficiais e subterrâneas originados de cemitérios, pois muitas dessas construções não consideram os fatores geológicos e hidrológicos da região (KEMERICH et al., 2012). Dessa maneira, os cemitérios são identificados como locais de alto risco de contaminação ambiental, pois devido ao processo de deterioração do corpo humano há liberação do necrochorume que possui várias substâncias químicas, como os metais pesados, material orgânico e com diversos constituintes patogênicos, além dos resíduos e componentes existentes no próprio caixão que contribui na liberação de constituintes para o solo e água subterrânea (KEMERICH et al., 2012; MIGLIORINI, 2002).
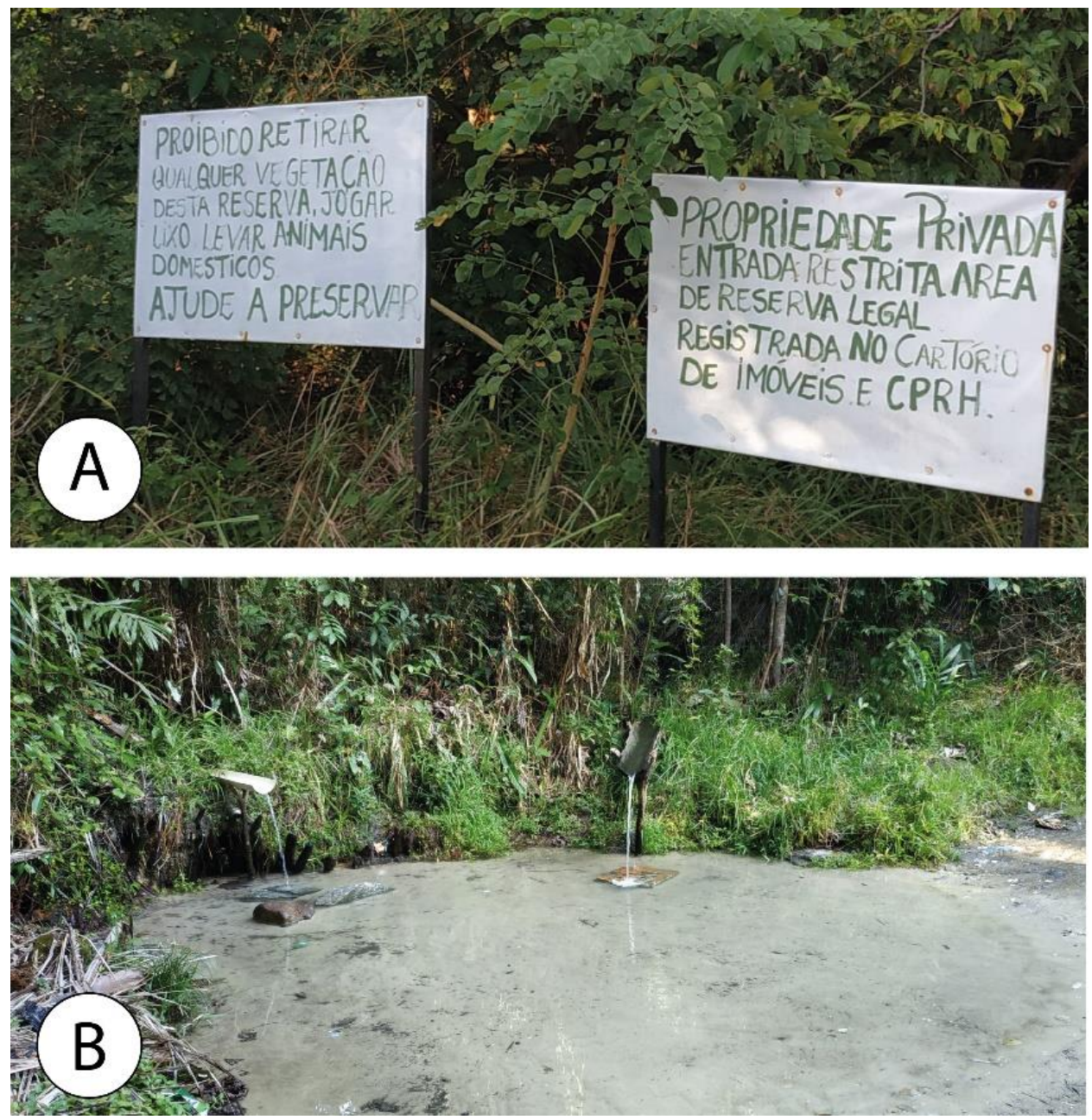

Figura 4. Visão geral do acesso e situação das nascentes. Fonte: O autor. 
USO DA ANÁLISE MULTIVARIADA COMO SUPORTE ESTATÍSTICO NA AVALIAÇÃO MACROSCÓPICA DOS IMPACTOS AMBIENTAIS EM NASCENTES NA LOCALIDADE DE CARNE DE VACA, PERNAMBUCO

\section{签} REVISTA GEONORTE

\section{Uso por animais e uso por humanos}

Em todas as nascentes foram encontrados indícios de uso por animal (marcas de pegadas, fezes e presença na região). Resultados semelhantes foram encontrados por Gomes et al. (2005) onde $68,75 \%$ das nascentes avaliadas possuem evidências de uso animal e por Pieroni et al., (2019) onde os autores encontraram em $28 \%$ das nascentes avaliadas uso intenso por animais.

O uso por humanos foi encontrado em todas as nascentes, sendo o uso principal a captação da água para utilização própria (Figura 5). Contudo, não foram realizadas análises sobre a qualidade dessas águas e se, de fato, essas águas são potáveis e seguras para o consumo humano e se estão enquadradas com o que sugere a Portaria $n^{\circ}$ 2.914/2011 do Ministério da Saúde (BRASIL, 2011).

A análise dos parâmetros físicos, químicos e biológicos referentes a qualidade da água para o consumo humano é essencial para a garantir a saúde e segurança das pessoas que utilizam desta água, pois quando contaminada torna-se um fator de risco para toda a sociedade (GERMANO; GERMANO, 2001). A preservação da qualidade da água exige atenção das autoridades sanitárias e consumidores, visto que o uso indevido pelos seres humanos pode tornar a água um meio de transmissão de agentes e doenças parasitárias e infecciosas que são responsáveis por cerca de $60 \%$ das doenças ocasionadas em humanos pelo uso de água com baixa qualidade (AMARAL et al., 2003).

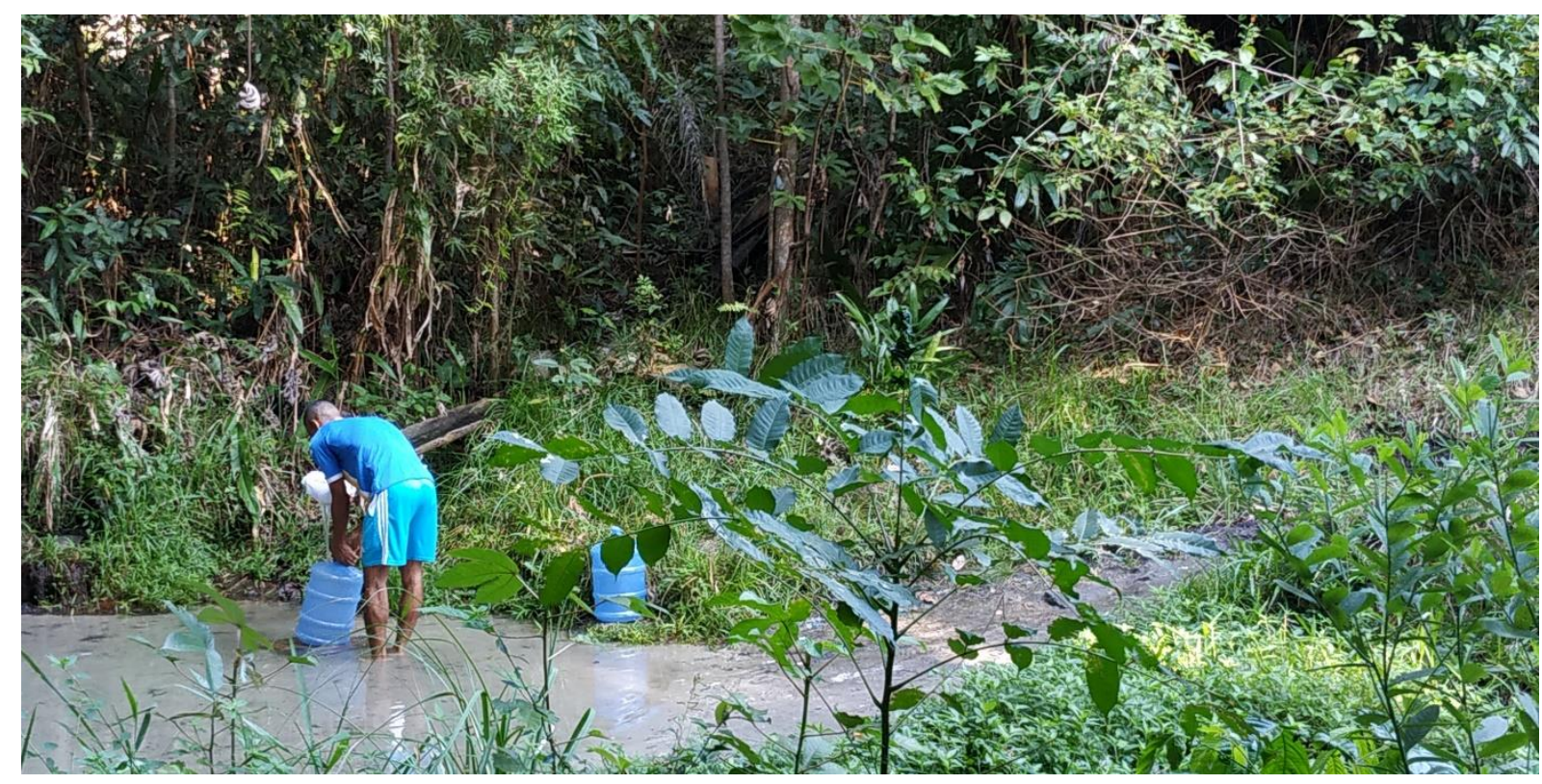

Figura 5. Uso das nascentes para captação da água para consumo da população local. Fonte: $\mathrm{O}$ autor. 
USO DA ANÁLISE MULTIVARIADA COMO SUPORTE ESTATÍSTICO NA AVALIAÇÃO MACROSCÓPICA DOS IMPACTOS AMBIENTAIS EM NASCENTES NA LOCALIDADE DE CARNE DE VACA, PERNAMBUCO

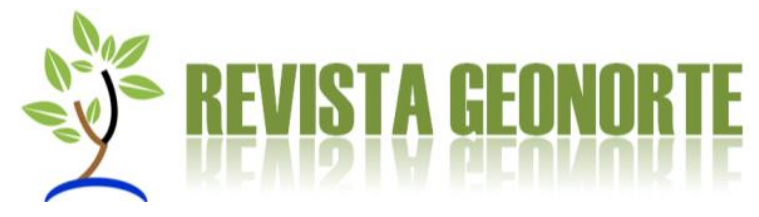

\section{Vegetação}

A vegetação encontra-se em processo de degradação, devido à retirada da mata ciliar nas proximidades das nascentes e ao longo da região são construídas trilhas para facilitar a chegada nesses corpos hídricos (Figura 6).

A retirada da vegetal gera inúmeros prejuízos ao meio ambiente, dentre eles: a diminuição da proteção dos corpos hídricos, aumento na taxa de erosão, elevação da temperatura local e proteção física ineficaz para retenção de materiais sólidos (PANIZZA, 2017).

A preservação da vegetação em nascentes é um parâmetro de difícil conservação, pois frequentemente são encontradas ocupações, presença de espécies invasoras, atividades de pastagem, acesso facilitado e falta de uma proteção adequada contribui com a degradação da vegetação e implicações sobre o bem-estar do meio ambiente (PIERONI et al., 2019; OLIVEIRA et al., 2013; FRANÇA JÚNIOR; VILLA, 2013; GOMES et al., 2005).

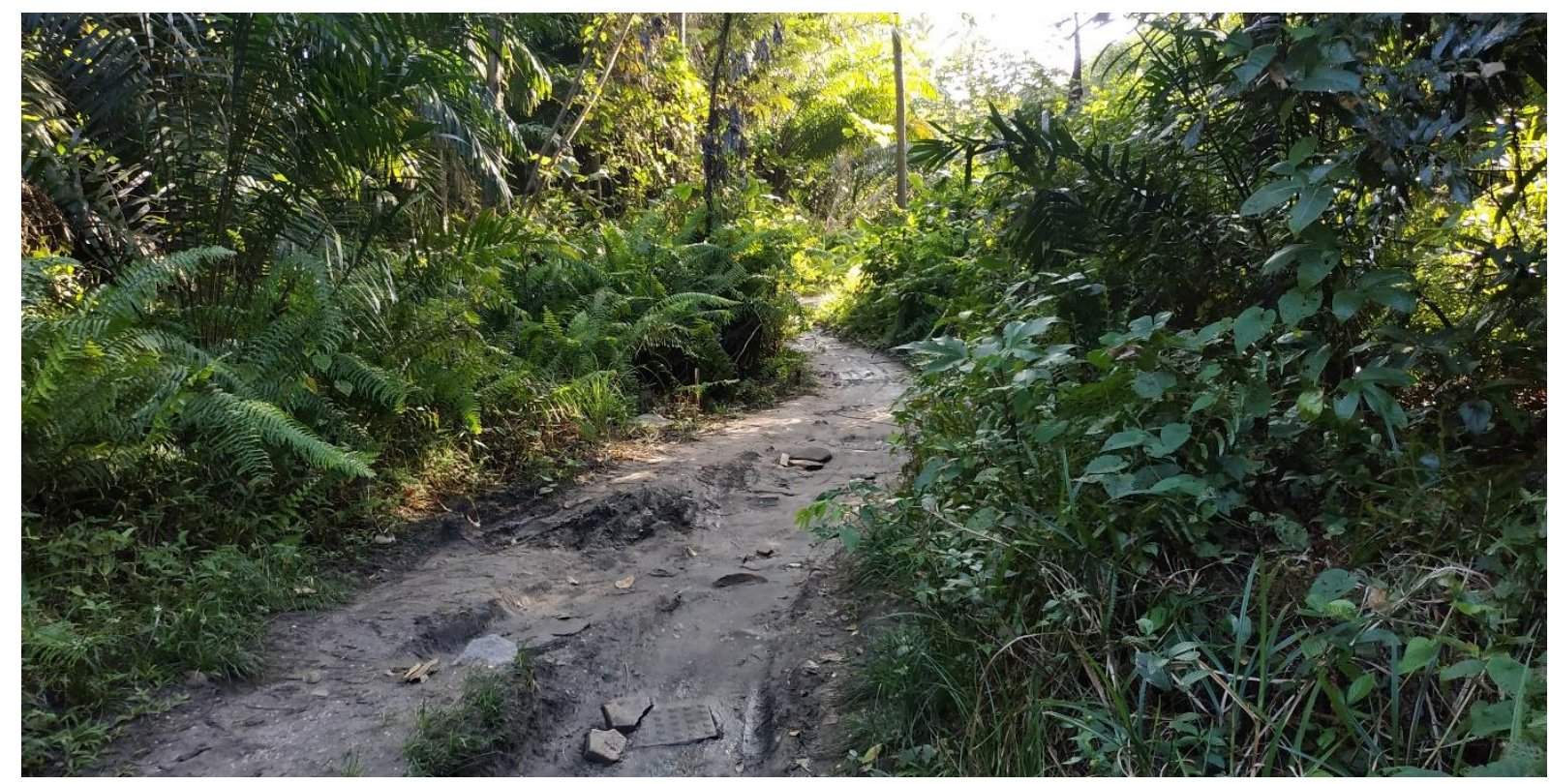

Figura 6. Desmatamento da vegetação local para facilitar o acesso às nascentes. Fonte: O autor.

\section{Análise estatística e classificação do grau de preservação das nascentes}

A análise dos componentes principais dos parâmetros avaliados, indicou que PC1 é responsável por $93,3 \%$ da variância total dos dados e possui forte correlação com lixo ao redor e proteção local $(r=0,96)$, enquanto PC2 explica $6,7 \%$ dos dados e possui correlações fracas $(r=0,26)$ com os parâmetros supracitados (Figura 7$)$. 
USO DA ANÁLISE MULTIVARIADA COMO SUPORTE ESTATÍSTICO NA AVALIAÇÃO MACROSCÓPICA DOS IMPACTOS AMBIENTAIS EM NASCENTES NA LOCALIDADE DE CARNE DE VACA, PERNAMBUCO

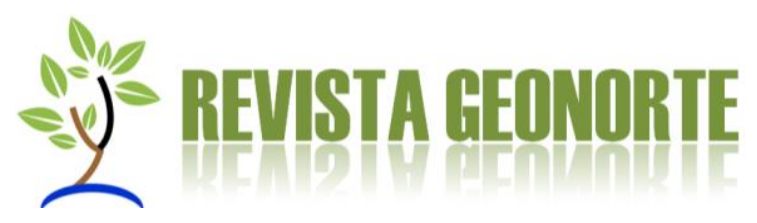

Através da ACP foi possível verificar a influência de cada parâmetro analisado sobre a qualidade das nascentes. Dessa maneira, percebe-se que a maioria dos parâmetros analisados possuem comportamento semelhante nas três nascentes avaliadas. Contudo, através dos parâmetros odor e lixo ao redor foi possível o reconhecimento de dois grupos com qualidades distintas.

O grupo formado no eixo positivo de PC1 indica a região com a melhor qualidade ambiental, dessa maneira a nascente 3 possui menor impacto ambiental e encontrase mais preservada. Porém, o grupo formado no eixo negativo de PC1 e eixos de PC2 através das nascentes 2 e 3 indicam regiões com as maiores pressões antrópicas em seu ecossistema e possivelmente com menor grau de conservação e consequentemente apresenta indícios de degradação ambiental.

Nesse contexto, através da ACP e IIAN, as nascentes possuem grau de preservação variando de ruim a razoável, o que sugere o impacto ambiental ocasionado pelas pessoas que utilizam as nascentes para a captação de água, refletindo na diminuição da qualidade da água, aumento da degradação da vegetação e nos processos erosivos, além de indicar a falta de fiscalização e consciência ambiental dos usuários.

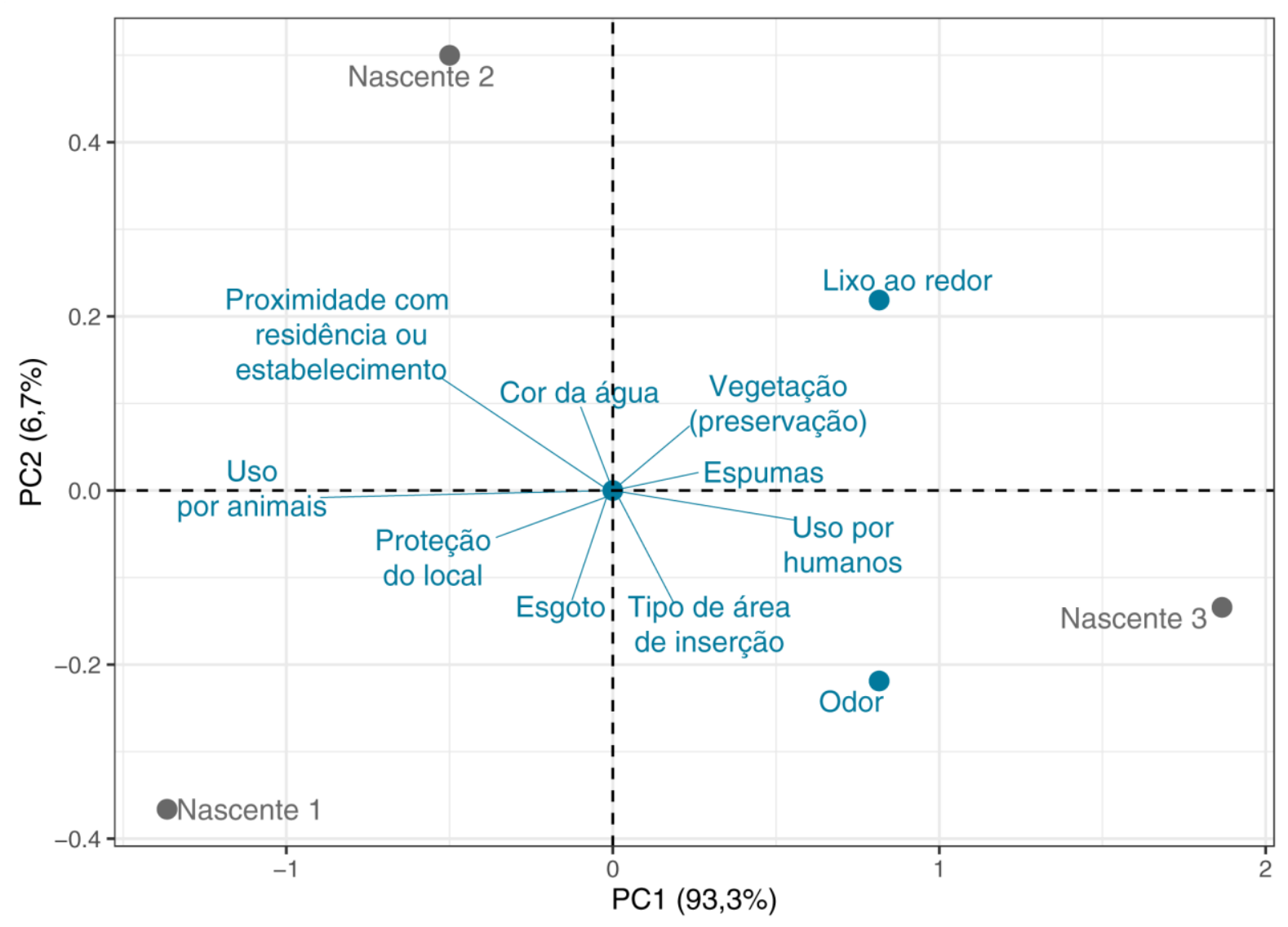

Figura 7. Distinção do grau de preservação das nascentes através da análise de componentes principais. Fonte: Elaborado pelo autor (2020). 
USO DA ANÁLISE MULTIVARIADA COMO SUPORTE ESTATÍSTICO NA AVALIAÇÃO MACROSCÓPICA DOS IMPACTOS AMBIENTAIS EM NASCENTES NA LOCALIDADE DE CARNE DE VACA, PERNAMBUCO

\section{CONSIDERAÇÕES FINAIS}

As nascentes localizadas no povoado de Carne de Vaca são importantes para a manutenção da qualidade ambiental e para o fornecimento de água para a população local, contudo encontram-se em processo de degradação ambiental e apresenta à necessidade de um monitoramento e gerenciamento ambiental contínuo.

Os principais impactos observados foram a presença de resíduos sólidos, falta de proteção, desmatamento da vegetação, a proximidade de cemitérios e o carente sistema de captação de água. Estes impactos são consequências do uso de forma desorganizada da população e através de suas atitudes contribuem no processo de degradação ambiental.

A aplicação da metodologia do Índice de Impacto Ambiental em Nascentes (IIAN) com a análise de componentes principais demonstram ser eficientes no processo de quantificação e agrupamento dos impactos existentes, permitindo a melhor apresentação dos dados e no entendimento dos resultados obtidos.

Nesse contexto, torna-se necessário realizar o monitoramento contínuo da região e atividades de educação ambiental para a conscientização da população sobre o uso do local e as consequências de suas atitudes. Recomendam-se estudos mais detalhados sobre a qualidade da água e verificar se é adequada para o consumo da população.

\section{AGRADECIMENTO}

À Coordenação de Aperfeiçoamento de Pessoal de Nível Superior (CAPES) pelo apoio científico concedido.

\section{REFERÊNCIAS}

AMARAL, L.A.; NADER FILHO, A.; ROSSI JUNIOR, O.D.; FERREIRA, F.L.A.; BARROS, L.S.S. Água de consumo humano como fator de risco à saúde em propriedades rurais. Revista de Saúde Pública. São Paulo, v. 37, n. 4, 2003.

BAKER, T.J.; MILLER, S.N. Using the Soil and Water Assessment Tool (SWAT) to assess land use impact on water resources in an East African watershed. Journal of Hydrology, v. 486, p. 100-111, 2013. https://doi.org/10.1016/j.jhydrol.2013.01.041

BRASIL. Ministério da Saúde. Fundação Nacional de Saúde. Manual de Saneamento/Ministério da Saúde, Fundação Nacional de Saúde. Brasília: Funasa, 2015. 642p. 
USO DA ANÁLISE MULTIVARIADA COMO SUPORTE ESTATÍSTICO NA AVALIAÇÃO MACROSCÓPICA DOS IMPACTOS AMBIENTAIS EM NASCENTES NA LOCALIDADE DE CARNE DE VACA, PERNAMBUCO

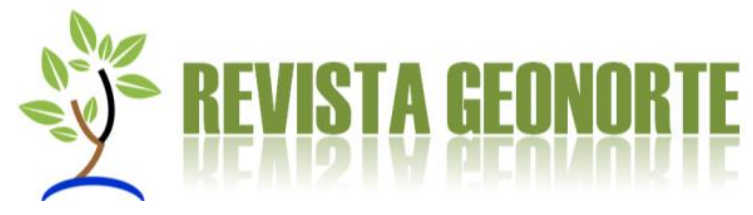

BRASIL. Ministério da Saúde. Portaria no 2914/MS de 2011. Disponível em: < https://bvsms.saude.gov.br/bvs/saudelegis/gm/2011/prt2914 1212 2011.html >. Acesso em: 14 de agosto de 2020.

BRASIL. Ministério da Saúde. Secretaria de Vigilância em Saúde. Vigilância e controle da qualidade da água para consumo humano. Ministério da Saúde, Secretaria de Vigilância em Saúde. - Brasília: Ministério da Saúde, 2006. 212p.

CASTRO, P.S.; LIMA, F.Z.; LOPES, J.D.S. Recuperação e Conservação de Nascentes. Viçosa: CPT, 2007. 272p.

CORREIO, L.N.C.; CECCONELLO, S.T.; MORAES, P.B.; GUEDES, H.A.S.; CENTENO, A.N.; CECCONELLO, S.T. Análise temporal da qualidade da água de um arroio no sul do Rio Grande do Sul. Revista Thema, v. 14, n. 2, p. 109-119, 2016. http://dx.doi.org/10.15536/thema.13.2016.109-119.363

CPRM. Projeto Cadastro de Fontes de Abastecimento de Águas Subterrâneas Diagnóstico do Município de Goiana. Ministério de Minas e Energia. Serviço Geológico do Brasil - CPRM, Diretoria de Hidrologia e Gestão Territorial. Recife, p. 2 - 5, 2005.

DANTAS, D.V.; BARLETTA, M.; COSTA, M. F.; BARBOSA-CINTRA, S.C.T.; POSSATTO, F.E.; RAMOS, J.A.A; LIMA, A.R.A.; SAINT-PAUL, U. Movement patterns of catfishes (Ariidae) in a tropical semi-arid estuary. Journal of Fish Biology, v. 76, $\mathrm{n}$. 10, p. 2540-2557, 2010. https://doi.org/10.1111/j.1095-8649.2010.02646.x

FERREIRA FILHO, S.S. Otimização da Aplicação do CAP no Tratamento de Água Visando a Redução de Compostos Orgânicos Causadores de Odor e Sabor em Águas de Abastecimento. Revista Engenharia Sanitária e Ambiental, v. 1, n. 4, p. 131-43, 1996.

FRANÇA JUNIOR, P.; VILLA, D.M.E.C. Análise macroscópica nas cabeceiras de drenagem da área urbana de Umuarama, região noroeste - Paraná/Brasil. Geografia Ensino \& Pesquisa, v. 17, n. 1, p. 107-118, 2013.

GERMANO, P.M.L.; GERMANO, M.I.S. A água: um problema de segurança nacional. Revista Higiene Alimentar, v.15, p.15- 18, 2001.

GOMES, P.M.; MELO, C.; VALE, V.S. Avaliação dos impactos ambientais em nascentes na cidade de Uberlândia-MG: análise macroscópica. Sociedade \& Natureza, v. 17, n.32, p. 103 - 120, 2005.

KEMERICH, P.D.C.; UCKER, F.E.; BORBA, W.F. Cemitérios como fonte de contaminação ambiental. Scientific American Brasil, v. 1, n. 123, p. 78-81, 2012.

KEMERICH, P.D.C; SILVA, J.L.S; BARROS, G.; BORBA, W.; UCKER, F.; FOLETTO, C. V. Chemical characterization of groundwater in the area occupied by the cemetery: 
USO DA ANÁLISE MULTIVARIADA COMO SUPORTE ESTATÍSTICO NA AVALIAÇÃO MACROSCÓPICA DOS IMPACTOS AMBIENTAIS EM NASCENTES NA LOCALIDADE DE CARNE DE VACA, PERNAMBUCO

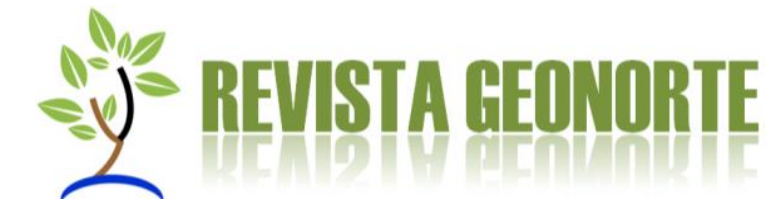

use of fluorescence spectrometry X-ray energy dispersive (EDXRF). Ambiente e Agua - An Interdisciplinary Journal of Applied Science, v. 7, n. 3, p. 166-182, 2012. http://dx.doi.org/10.4136/ambi-agua.911

MARTINS, A.P.F.; TERTO, R.S.; LIMA, J.R.; OLIVEIRA, E. Estudo de Impactos Ambientais na comunidade quilombola Serra Feia - Cacimbas-PB. Agropecuária $\begin{array}{llllll}\text { Científica no semi-árido, v. 13, p. } 121-129, & 2017 .\end{array}$ http://dx.doi.org/10.30969/acsa.v13i2.815

MEDEIROS, S.R.M.; CARVALHO, R.G.; SOUZA, L.; BARBOSA, A.H.S. Índice de qualidade das águas e balneabilidade no Riacho da Bica, Portalegre, RN, Brasil. Revista Ambiente e Água [online], v. 11, p. 711-730, 2016. http://dx.doi.org/10.4136/ambi-agua. 1833

MIGLIORINI, R.B. Cemitérios contaminam o meio ambiente: um estudo de caso. Cuiabá: Universitária, 2002. 50 p.

MINGOTI, S.A. Análise de dados através de Métodos de Estatística Multivariados. 1. ed. Minas Gerais: UFMG, 2005. 295p.

OLIVEIRA, M.C.P; OLIVEIRA, B.T.A.O; DIAS, M.M.N; SILVA, B.M; SILVA, S.V.B; FELIPPE, M.F. Avaliação macroscópica da qualidade das nascentes do campus da Universidade Federal de Juiz de Fora. Revista Geografia. v. 3, n. 1, 2013.

OLIVEIRA, P.F.; DELEVATI, D.; COSTA, A.B.; ALCAYAGA, E.L. Avaliação da qualidade da água de nascentes na bacia hidrográfica do Arroio Andréas, RS, utilizando variáveis físicas, químicas e microbiológicas. Revista Jovens Pesquisadores, v. 4, n. 1, p. 32-41, 2014. http://dx.doi.org/10.17058/rjp.v4i1.4607

PANIZZA, A. C. A importância da Mata ciliar: Entenda por que as formações vegetais ciliares são essenciais para os ecossistemas e para os recursos hídricos. São Paulo. 2017. Disponível em: https://www.cartacapital.com.br/educacao/a-importancia-damata-ciliar/. Acesso em 25 agosto de 2020.

PIERONI, J.P.; BRANCO, K.G.R.; DIAS, G.R.V.; FERREIRA, G. C. Avaliação do estado de conservação de nascentes em microbacias hidrográficas. GEOCIÉNCIAS (SÃO PAULO. ONLINE), v. 38, p. 185-193, 2019.

R CORE TEAM. R: A language and environment for statistical computing. $R$ Foundation for Statistical Computing, Vienna, Austria. 2020.

SANTANA, N.R.F; AGUIAR NETO, A.O; SILVA, M.G.; GARCIA, C. A. B. Índice de qualidade da água nas nascentes do rio Piauitinga-SE por análise multivariada e o uso na irrigação. Rev. Bras. Agric. Irr., v. 10, n. 6, p. 999-1010, 2016. DOI: 10.7127/rbai.v10n600441 
USO DA ANÁLISE MULTIVARIADA COMO SUPORTE ESTATÍSTICO NA AVALIAÇÃO MACROSCÓPICA DOS IMPACTOS AMBIENTAIS EM NASCENTES NA LOCALIDADE DE CARNE DE VACA, PERNAMBUCO

SOARES, A. B.; TROLEIS, A. L. Impactos socioambientais na qualidade da água da nascente Pau Amarelo em Garanhuns-Pe. Revista de geografia (Recife), v. 34, p. 160185, 2017.

SOUZA, A.; SANTOS, D.A.S. Análise das componentes principais no processo de monitoramento ambiental. Nativa, v. 6, p. 639, 2018. http://dx.doi.org/10.31413/nativa.v6i6.6453

TORRES, F.T.P. Mapeamento e análise de impactos ambientais das nascentes do Córrego Alfenas, Ubá (MG). Revista de Ciências Agro-Ambientais (Online), v. 14, p. 42-52, 2016. 